\title{
Effect of sponge volume fraction on the performance of a novel fluidized bed bioreactor
}

\author{
T. T. Nguyen, H. H. Ngo* and W. S. Guo \\ Faculty of Engineering and Information Technology, University of Technology, Sydney, Broadway, NSW 2007, Australia \\ * H. H. Ngo (corresponding author); E-mail: h.ngo@uts.edu.au
}

\begin{abstract}
A novel fluidized bed bioreactor (FBBR) was designed by integration of anaerobic granular activated carbon and aerobic sponge reactors. This FBBR was evaluated at different sponge volume fractions for treating a synthetic wastewater. Polyester urethane sponge with cube size of $1 \times 1 \times 1 \mathrm{~cm}$ and density of $28-30 \mathrm{~kg} / \mathrm{m}^{3}$ with 90 cells per $25 \mathrm{~mm}$ was used as biomass carrier. The results indicate that the FBBR could remove more than $93 \%$ of dissolved organic carbon (DOC). The highest nutrient removal efficiencies (58.2\% $\mathrm{PO}_{4}-\mathrm{P}$ and $75.4 \% \mathrm{NH}_{4}-\mathrm{N}$ ) were achieved at $40 \%$ sponge volume fraction. The system could provide a good condition for biomass growth (e.g. $186.2 \mathrm{mg}$ biomass/g sponge). No significant different performance in specific oxygen uptake rate was observed between 30,40 , and $50 \%$ sponge volume fractions.
\end{abstract}

Key words | fluidized bed bioreactor, granular activated carbon, primary treated sewage effluent, sponge reactor

\section{INTRODUCTION}

To ensure a stable and reliable operation of a micro-filtration (MF) hybrid system in primary treated sewage effluent treatment for reuse, a pre-treatment of raw wastewater prior to $\mathrm{MF}$ is essential for controlling membrane fouling and reducing contaminant loading. Feed pre-treatment is a key factor determining the success or failure of a desalination installation and influences the overall performance of the plant. Traditional pre-treatment is based on the removal of suspended material (by processes such as flocculation, and deep bed filtration), supported by an extensive chemical treatment, including bio-fouling control (chlorination, dechlorination), and scaling prevention. As a result, the pretreatment and cleaning accounts for a significant part of the total cost. The above pre-treatments do not remove dissolved organic matter, which is mainly responsible for membrane fouling. Thus it is necessary to go for a new generation of pre-treatment methods to reduce organic fouling and thus reduce the operational and energy costs of a filtration system.

As a consequence, there are a wide variety of potential pre-treatment options for MF including dual or single media filtration, softening and/or ion exchange, granular activated carbon (GAC) filters, $\mathrm{pH}$ adjustment, etc. (DuPont 1994; Ajay et al. 2006). A potential process in the treatment train is biological pre-treatment of the water to reduce the organic constituents that either contribute directly to organic fouling or provide carbon sources for the development of biofilms on the membrane surfaces (Rusten et al. 1999; Show \& Tay 1999). Among the biological treatment methods, the application of fluidization in the field of environmental technology has increased considerably. The fluidized bed bioreactor (FBBR) has several advantages over other conventional reactors for the treatment of wastewater (Perez et al. 2001; Xie et al. 2004;

Vasiliadou et al. 2009). Treatment of industrial wastewaters requires a great deal of space when using systems based on activated sludge in which the retention time is many days. On the other hand, a FBBR is capable of achieving treatment in low retention time because of the high biomass concentrations that can be achieved in a reactor. The bed, consisting of small particles, offers a vast surface area for microbial growth in the state of fluidization. This enables far greater microbial concentration than that maintained in the activated sludge process and in the conventional fixed bed systems such as a trickling filter, rotating disc filter and submerged contact oxidation.

Use of GAC in fluidized bed reactors (GAC-FBR) is an emerging technology for difficult to degrade organics, 
operated under anaerobic conditions. The GAC provides a temporary storage place, through adsorption (Shi et al. 1995), for occasions when the contaminant concentration is in excess of the bacterial capacity to transform it. The anaerobic fluidized bed GAC bioreactor (AFBGAC) has been proven as an efficient treatment method for coal gasification wastewater and wastewater containing chlorinated hydrocarbons and phenols (Suidan et al. 1991;

Flora et al. 1994). A sequential system consisting of an AFBGAC bioreactor followed by an activated sludge reactor was effective in the treatment of wastewater containing dinitrotoluene and trinitrotoluene (VanderLoop et al. 1994). The AFBGAC reactor removes organic matter through a combination of physical adsorption and biological transformation (Perez et al. 2007; Fernandez et al.

2008; Haroun \& Idris 2009). Some studies showed success using GAC and sand as support media in perchlorate- reducing packed and fluidized beds treating contaminated

groundwater (Kim \& Logan 2000; Brown et al. 2006). Another study comparing the performance of sand- and GAC-filled FBRs found that both beds removed similar amounts of perchlorate from groundwater. When the beds were fed groundwater, the GAC-filled FBR performed slightly better.

The integration of two advanced supporting media in a single system could evaluate the promising FBR for a MF system. The objective of this study is to assess the effect of sponge volume fractions on this novel FBBR. The performance of the system was monitored based on the removal efficiencies of dissolved organic carbon (DOC) and nutrient (nitrogen and phosphorus), specific oxygen uptake rate (SOUR), and biomass growth on the carrier media.

\section{MATERIALS AND METHODS}

\section{Synthetic wastewaters}

The experiments were conducted using a synthetic wastewater to avoid any fluctuation in the feed concentration and provide the continuous source of biodegradable organic pollutants such as glucose, ammonium sulfate and potassium dihydrogen orthophosphate. The wastewater also contained refractory organic pollutants such as humic acid, arabic acid and acacia gum powder. It was used to simulate high-strength domestic wastewater (just after primary treatment process). The synthetic wastewater consists of DOC of $120-130 \mathrm{mg} / \mathrm{L}$, chemical oxygen demand (COD) of 330-360 mg/L, ammonium nitrogen $\left(\mathrm{NH}_{4}-\mathrm{N}\right)$ of $12-15 \mathrm{mg} / \mathrm{L}$ and orthorphosphate ( $\mathrm{PO}_{4}-\mathrm{P}$ ) of 3.3-3.5 mg/L (COD:N:P 1/4 100:5:1). The composition of synthetic wastewater used in this study is shown in Table 1 (Lee et al. 2003).

\section{GAC and sponge used}

A coal-based GAC (Acticarb GS1300, Activated Carbon Technologies Pty Ltd, Australia) was used in this study. This coal-based GAC has a surface area of $>1,100 \mathrm{~m}^{2} / \mathrm{g}$ (BET; Brunauer-Emmett-Teller), an iodine number of $>1,100 \mathrm{mg} /(\mathrm{g} \mathrm{min})$ and maximum ash and moisture contents of 10 and $3 \%$, respectively. Prior to use in experiments, the GAC was rinsed with distilled water to remove fines and dried at $105{ }^{\mathrm{w}} \mathrm{C}$ in the oven. Polyesterurethane sponge was used in the study, namely $\mathrm{S}_{28-30} / 90 \mathrm{R}$ (density of $28-30 \mathrm{~kg} / \mathrm{m}^{3}$ with 90 cells per $25 \mathrm{~mm}$ ) with the dimensions of $1 \times 1 \times 1 \mathrm{~cm}$.

Table 1 | Composition and concentration of the synthetic wastewater

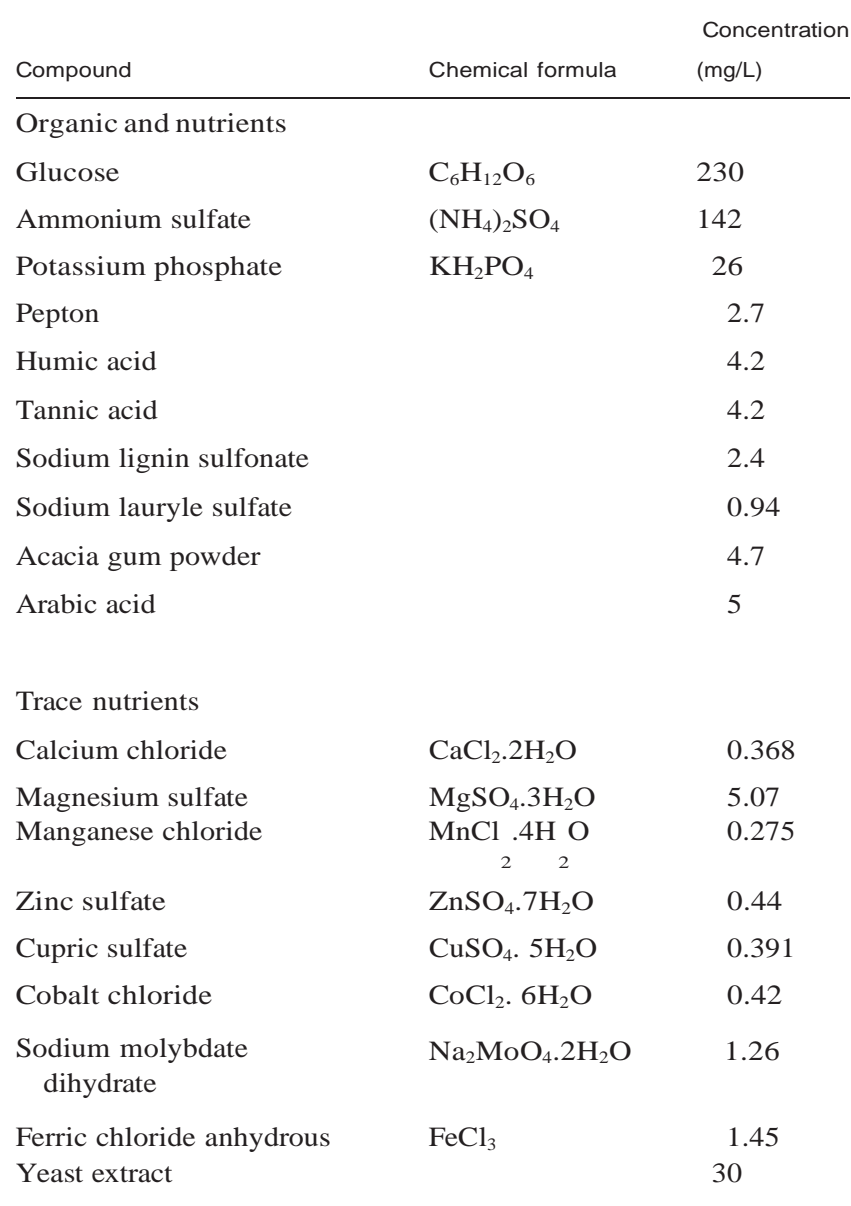




\section{Fluidized bed bioreactor description}

The FBBR consisted essentially of two parts, the column and the conical-shaped reactor (Figure 1). The reactor column itself had a height of $100 \mathrm{~cm}$ with an inside diameter of $2.5 \mathrm{~cm}$, and attached to this was an upper conical-shaped reactor with total and working volume of 4.3 and $3.8 \mathrm{~L}$, respectively.

Two hundred milliliters of GAC (70 g) was added to the column as a carrier media for biomass attachment. Sponge cubes with dimension of $1 \times 1 \times 1 \mathrm{~cm}$ were used in the upper part as a sponge reactor with four different sponge volume fractions (Table 2). The GAC column was operated under anaerobic condition, whereas the sponge reactor was maintained under aerobic condition by supplying air with the flow rate of $3 \mathrm{~L} / \mathrm{min}$. Influent wastewater was pumped in continuously at the bottom of the reactor by means of a peristaltic pump with the flow rate of $20 \mathrm{~mL} /$ min and effluent was withdrawn from the top. The output from the sponge reactor was also recycled back to the bottom of the reactor using a recycle pump operated at a constant rate of $110 \mathrm{~mL} / \mathrm{min}$ (85\% recirculation), enough

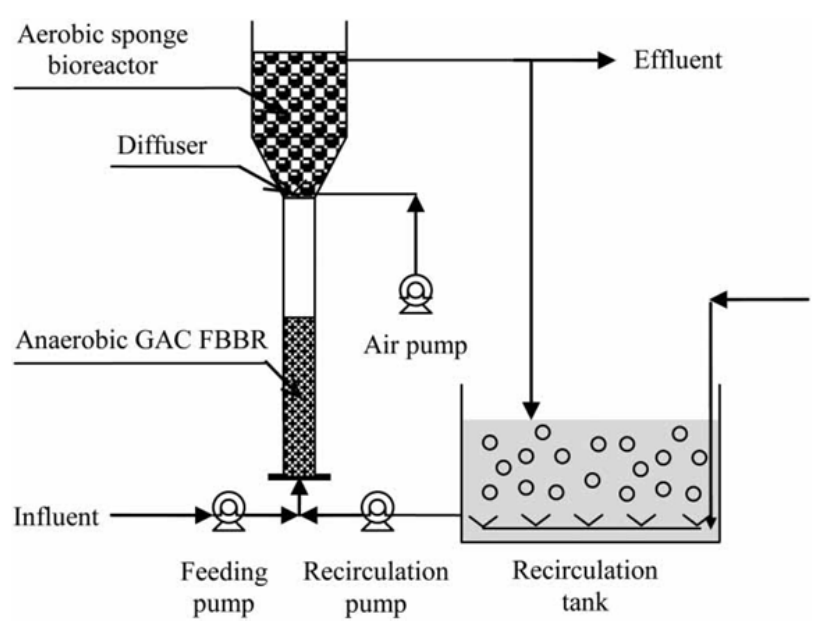

Figure 1 | Schematic diagram of the FBBR.

\begin{tabular}{|c|c|c|c|}
\hline Stage & Sponge volume fraction (\%) & $\begin{array}{l}\text { Organic loading rate } \\
\left(\mathrm{kg} \mathrm{COD} /\left(\mathrm{d} \cdot \mathrm{m}_{\mathrm{G} A C}^{3}+\text { sponge }\right)\right)\end{array}$ & HRT (min) \\
\hline I & 20 & 8.64 & 50 \\
\hline II & 30 & 6.17 & 70 \\
\hline III & 40 & 4.80 & 90 \\
\hline IV & 50 & 3.93 & 110 \\
\hline
\end{tabular}

to provide complete fluidization of the GAC. This recycle rate created essentially well-mixed conditions in the reactor. Nitrogen gas was applied to the recirculation reactor in order to maintain the anaerobic condition for the recirculated water.

\section{Analysis}

DOC of the influent and effluent was measured using the Analytikjena Multi N/C 3100. N-NH 4 and $\mathrm{P}_{4} \mathrm{PO}_{4}$ were measured by a photometric method using Spectroquant ${ }^{\circledR}$ Cell Test (NOVA 60, Merck). For measuring the biomass of sponge, three sponge cubes from each of the stages were rinsed with Milli-Q water to remove all of the biomass. Biomass, monitored as mixed liquor volatile suspended solids (MLVSS), was determined according to APHA (1998) standard method. A YSI 5300 biological oxygen monitor was used to measure the SOUR. The oxygen consumption measurement can be achieved through the use of an oxygen electrode with an oxygen-permeable Teflon membrane. Voltage generated from the reaction is proportional to the oxygen concentration of the sample and produces oxygen uptake during a period of 2-15 min.

\section{RESULTS AND DISCUSSION}

$\mathrm{pH}$, oxidation-reduction potential, and dissolved oxygen

Figure 2 shows the $\mathrm{pH}$, oxidation-reduction potential (ORP) and dissolved oxygen (DO) in the sponge reactor and recirculation reactor. The $\mathrm{pH}$ of the sponge reactor and recirculation reactor was about $6.5-7.5$ at stage I of the experiment. However, $\mathrm{pH}$ was reducing with time and reached 5.0-6.0 at stage IV. ORP was maintained between 170 and $220 \mathrm{mV}$ in the sponge reactor by supplying oxygen. ORP of the recirculation reactor was always below 0 . The DO concentration was maintained at 3.8-5.1 mg/L for the aerobic condition in the sponge reactor and less than $0.5 \mathrm{mg} / \mathrm{L}$ in the recirculation reactor, indicating the anaerobic condition was sustained.

\section{Organic and nutrient removal}

The organic and nutrient removal efficiencies of the FBBR system are shown in Table 3. The experimental results showed that the FBBR system was successful at removing organic with the efficiency over $92 \%$ in every condition. 

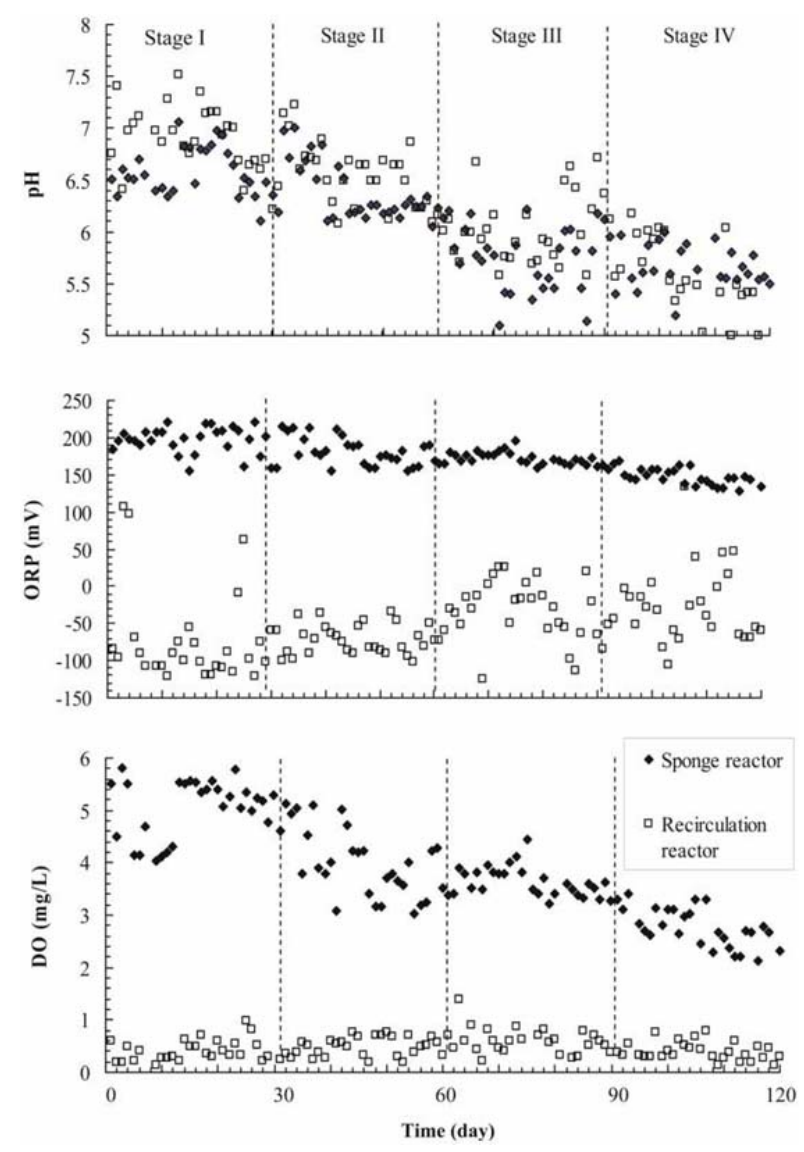

Figure $2 \mid \mathrm{pH}, \mathrm{ORP}$, and $\mathrm{DO}$ of the sponge reactor and recirculation reactor.

Table 3 | Organic and nutrient removal efficiency of the FBBR (\%)

\begin{tabular}{|c|c|c|c|c|}
\hline & Stage I & Stage II & Stage III & Stage IV \\
\hline DOC removal & $92.6 \pm 4.0$ & $93.1 \pm 1.5$ & $95.3 \pm 1.8$ & $96.6 \pm 1.5$ \\
\hline $\mathrm{P}-\mathrm{PO}_{4}$ removal & $56.8 \pm 4.8$ & $50.3 \pm 5.0$ & $53.3 \pm 4.5$ & $53.5 \pm 4.7$ \\
\hline $\mathrm{N}-\mathrm{NH}_{4}$ removal & $51.2 \pm 14.6$ & $58.8 \pm 2.9$ & $73.9 \pm 8.4$ & $63.0 \pm 3.3$ \\
\hline
\end{tabular}

DOC removal was about $92.6 \%$ in stage I and increased gradually to $96.6 \%$ in stage IV. It is demonstrated that there was no significant difference between sponge volume fraction of 20 and $50 \%$ in terms of organic removal efficiency. Xing et al. (2010) evaluated the performance of an anaerobic GAC FBBR and the study showed that the system could only remove around $60 \%$ of organic matter. Thus, this novel FBBR is able to perform better in terms of DOC removal as compared to the anaerobic FBBR system.

There also was no correlation between phosphorus removal efficiency and amount of sponge in the bioreactor. The highest efficiency was found to be $56.8 \%$ at stage I. The FBBReliminated 50.3, 53.3, and 53.5\% $\mathrm{P}-\mathrm{PO}_{4}$ at stage II, III, and IV, respectively. A clear effect of sponge volume fraction on $\mathrm{N}-\mathrm{NH}_{4}$ removal was observed. $\mathrm{N}-\mathrm{NH}_{4}$ removal at $20 \%$ sponge volume was $51.2 \%$. It increased to $58.8 \%$ in stage II (30\% sponge volume). The highest $\mathrm{N}-\mathrm{NH}_{4}$ removal efficiency of $73.9 \%$ was noticed in stage III, followed by a slump to $63.0 \%$ in the next stage. The increasing of $\mathrm{N}-\mathrm{NH}_{4}$ removal resulted from the increasing number of ammonium-oxidizing bacteria, which was proportional to the amount of biomass produced by the sponge. At $50 \%$ of sponge volume fraction, the sponge was actually not moving freely in the reactor, wastewater flowed through some gap between the sponges, and less contact with biomass occurred, thus resulting in the decreasing of $\mathrm{N}-\mathrm{NH}_{4}$ removal.

\section{Sponge biomass}

Figure 3 shows the biomass attached on sponge at four different stages of the experiment. The results clearly indicate that lowest biomass was noticed when the system operated at stage I (20\% of sponge volume). It started with $39 \mathrm{mg}$ biomass/g sponge, followed by a slight increase to $54 \mathrm{mg}$ biomass/g sponge. From day 10 of stage I, the biomass remained stable at about $130-135 \mathrm{mg}$ biomass/g sponge. At stage II, sponge biomass varied from 175 to $185 \mathrm{mg}$ biomass/g sponge during the first 5 days of the stage to $115 \mathrm{mg}$ biomass/g sponge in day 10. A significant increase of sponge biomass was observed on day 15; however, it was stable between 180 and $210 \mathrm{mg}$ biomass/g sponge from day 20.

Sponge biomass value was in a steady stage in both 40 and $50 \%$ of sponge volume. Additionally, biomass in stage III was 170-190 mg biomass/g sponge, slightly higher than that in stage IV (145-165 mg biomass/g sponge). According

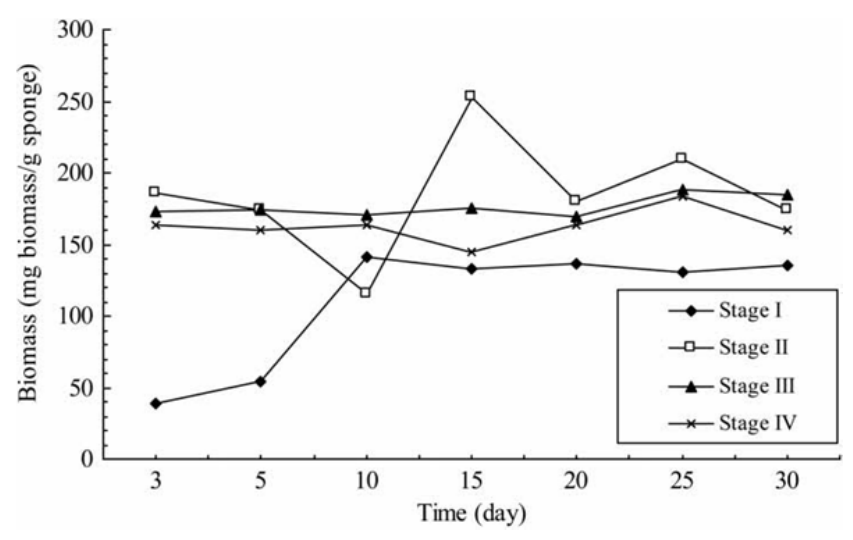

Figure 3 | Sponge biomass at four different stages. 
Table 4 | DO consumption and SOUR of sponge biomass

\begin{tabular}{lllll} 
& Stage I & Stage II & Stage III & Stage IV \\
\hline $\begin{array}{c}\text { DO consumption } \\
\text { for 16 min (\%) }\end{array}$ & $55.6 \pm 1.6$ & $34.2 \pm 6.8$ & $32.0 \pm 2.7$ & $30.5 \pm 2.4$ \\
$\begin{array}{c}\text { SOUR }(\mathrm{mg} \mathrm{O} / \\
(\mathrm{gVSS} \cdot \mathrm{h}))\end{array}$ & $57.2 \pm 7.0$ & $26.7 \pm 7.1$ & $27.4 \pm 3.1$ & $27.8 \pm 2.6$ \\
\hline
\end{tabular}

to Perez et al. (2001) biomass growth on the support media is proportional to the organic loading rate, and the extremely high biomass concentration can be maintained in the system because biofilm thickness is limited by the liquid flow rate applied. This is due to the fact that the FBBR retains the growth support medium in suspension by drag forces exerted by up-flowing wastewater, and the distribution of biomass hold-up is thus relatively uniform. These results demonstrated that sponge biomass at stage III (40\% sponge volume fraction) was more stable and highest in amount.

\section{Respiration test and SOUR}

Respiration tests were conducted using a YSI 5300 biological oxygen monitor for testing the impact of sponge volume fraction on microbial activity or oxygen transfer. As shown in Table 4, in stage I, the DO consumption measured was $55.6 \%$ in accordance with SOUR of $57.2 \mathrm{mg} \mathrm{O} /$ (g VSS·h). Stages II, III, and IV exhibited 34.2, 32.0, and 30.5\% of DO consumption for $16 \mathrm{~min}$, respectively.

SOUR also shows a similar microbial activity when the system achieved about $27 \mathrm{mg} \mathrm{O} /(\mathrm{g}$ VSS·h) in stages II, III, and IV. The highest SOUR value was observed at $57.2 \mathrm{mg} \mathrm{O}_{2} /(\mathrm{g} \mathrm{VSS} \cdot \mathrm{h})$ when the system operated at $20 \%$ sponge volume fraction. The different value of both DO and SOUR of stage I, compared with the other stages, could be explained by the food to micro-organism ratio (F/M ratio). At the lower sponge volume fraction, the amount of biomass was relatively less, the micro-organisms utilized more organics, and so consumed more oxygen.

\section{CONCLUSIONS}

- The integrated FBBR system with GAC and sponge could successfully remove dissolved organic carbon in a synthetic wastewater.

- The highest $\mathrm{N}-\mathrm{NH}_{4}$ removal efficiency was observed when the system operated at stage III (40\% sponge volume fraction).
- The most stable and highest amount of sponge biomass was also noticed at stage III of the experiment.

- The SOUR value of sponge biomass depended on the $\mathrm{F} / \mathrm{M}$ ratio of the system.

\section{ACKNOWLEDGEMENT}

This work was funded by an Australian Research Council (ARC) Industry Linkage Grant (LP10775149).

\section{REFERENCES}

Ajay, P., Zhu, J. \& Nakhla, G. 2006 Simultaneous carbon, nitrogen and phosphorous removal from municipal wastewater in a circulating fluidised bed bioreactor. Chemosphere 65, 1103-1112.

APHA 1998 Standard Methods for the Examination of Water and Wastewater, 20th edn, American Public Health Association/ American Water Works Association/Water Environment Federation, Washington, DC, USA.

Brown, D., Fuchino, T. \& Marechal, F. 2006Solid fuel decomposition modelling for the design of biomass gasification systems. Computation Chemical Engineering 21, 1661-1666.

DuPont de Nemoun International S.A. 1994Quality approval programme for filter media. Filtration and Separation 31, 16.

Fernández, N., Montalvo, S., Borja, R., Guerrero, L., Sánchez, E., Cortés, I., Colmenarejo, M. F., Travieso, L. \& Raposo, F. 2008 Performance evaluation of an anaerobic fluidized bed reactor with natural zeolite as support material when treating high-strength distillery wastewater. Renewable Energy 33, 2458-2466.

Flora, J. V. R., Suidan, M. T., Wuellner, A. M. \& Boyer, T. K. 1994 Anaerobic treatment of a simulated high strength industrial wastewater containing chlorophenol. Water Environmental Resource 66, 21-31.

Haroun, M. \& Idris, A. 2009 Treatment of textile wastewater with an anaerobic fluidized bed reactor. Desalination 237, 357-366.

Kim, K. \& Logan, B. E. 2000Microbial reduction of perchlorate in pure and mixed culture packed-bed bioreactors. Water Research 35, 3071-3076.

Lee, W., Kang, S. \& Shin, H. 2003 Sludge characteristics and their contribution to microfiltration in submerged membrane bioreactors. Journal of Membrane Science 216, 217-227.

Perez, M., Rodriguez-Cano, R., Romero, L. I. \& Sales, D. 2007 Performance of anaerobic thermophilic fluidized bed in the treatment of cutting-oil wastewater. Bioresource Technology 98, 3456-3463.

Perez, M., Romero, L. I. \& Sales, D. 2001 Organic matter degradation kinetic in an anaerobic thermophilic fluidised bed bioreactor. Anaerobe 7, 25-35.

Rusten, B., Johnson, C. H., Devall, S., Davoren, D. \& Cashion, B. S. 1999 Biological pre-treatment of chemical plant wastewater 
in high rate moving bed biofilm reactor. Water Science and Technology 39, 257-264.

Shi, J., Zhao, X., Hickey, R. F. \& Voice, T. C. 1995 Role of adsorption in granular activated carbon fluidised bed reactors. Water Environmental Resource 67, 302-309.

Show, K. Y. \& Tay, J. H. 1999 Influent of support media on biomass growth and retention in anaerobic filters. Water Research 33, 1471-1481.

Suidan, M. T., Wuellner, A. M. \& Boyer, T. K. 1995 Anaerobic treatment for a high strength industrial waste bearing inhibitory concentration of 1,1,1-trichloroethane. Water Science and Technology 23, 1385.

VanderLoop, S. L., Suidan, M. T., Moteleb, M. A. \& Maloney, S. W. 1994 Effects of molecular oxygen on GAC adsorption of energetics. Proceedings from the 67th WEF Annual Conference and Exposition, Chicago, IL, USA.

Vasiliadou, I. A., Karanasios, K. A., Pavlou, S. \& Vayenas, D. V. 2009 Experimental and modelling study on drinking water hydrogenotrophic denitrification in packed-bed reactors. Journal of Hazardous Materials 165, 812-824.

Xie, W., Wang, Q., Song, G., Kondo, M., Teraoka, M., Ohsumi, Y. \& Ogawa, H. I. 2004Upflow biological filtration with floating filter media. Process Biochemistry 39, 765-770.

Xing, W., Ngo, H. H., Guo, W. S., Wu, Z., Nguyen, T. T., Cullum, P., Listowski, A. \& Yang, N. 2010 Enhancement of the performance of anaerobic fluidised bed bioreactors (AFBBRs) by a new starch based flocculant. Separation and Purification Technology 72, 140-146. 